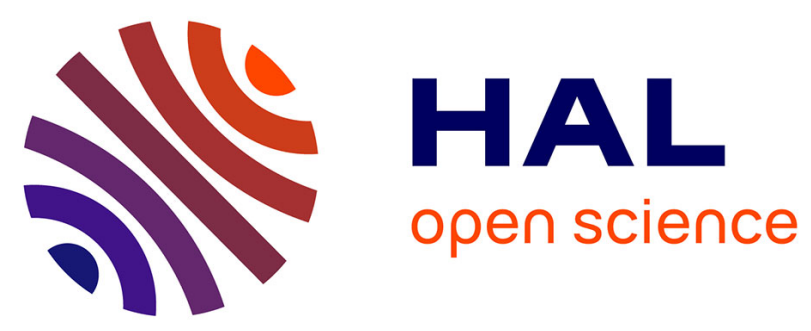

\title{
APACHES: Human-Centered and Project-Based Methods in Higher Education
}

\author{
Mathieu Vermeulen, Abir B Karami, Anthony Fleury, François Bouchet, \\ Nadine Mandran, Jannik Laval, Jean-Marc Labat
}

\section{- To cite this version:}

Mathieu Vermeulen, Abir B Karami, Anthony Fleury, François Bouchet, Nadine Mandran, et al.. APACHES: Human-Centered and Project-Based Methods in Higher Education. 14th European Conference on Technology Enhanced Learning EC-TEL 2019, Sep 2019, Delft, Netherlands. pp.683-687, 10.1007/978-3-030-29736-7_66. hal-02290443

\section{HAL Id: hal-02290443 \\ https://hal.science/hal-02290443}

Submitted on 9 Dec 2019

HAL is a multi-disciplinary open access archive for the deposit and dissemination of scientific research documents, whether they are published or not. The documents may come from teaching and research institutions in France or abroad, or from public or private research centers.
L'archive ouverte pluridisciplinaire HAL, est destinée au dépôt et à la diffusion de documents scientifiques de niveau recherche, publiés ou non, émanant des établissements d'enseignement et de recherche français ou étrangers, des laboratoires publics ou privés. 


\title{
APACHES: Human-centered and project-based methods in higher education
}

\author{
Mathieu Vermeulen ${ }^{10000-0003-3646-1741]}$, Abir Karami ${ }^{2}$, Anthony \\ Fleury $^{1[0000-0002-0175-3181]}$, François Bouchet ${ }^{3[0000-0001-9436-1250]}$, Nadine \\ Mandran ${ }^{4}$, Jannik Laval ${ }^{5}$, and Jean-Marc Labat ${ }^{3}$ \\ 1 IMT Lille Douai, Université de Lille, Lille \\ \{mathieu.vermeulen, anthony.fleury\}@imt-lille-douai.fr \\ 2 FGES-Université Catholique de Lille, Lille. abir.karami@imt-lille-douai.fr \\ 3 Sorbonne Université, CNRS, LIP6, F-75005 Paris \\ \{françois.bouchet, jean-Marc.labat\}@lip6.fr \\ 4 Université Grenoble ALPES, Grenoble. nadine.mandran@imag.fr \\ 5 DISP, Université Lyon 2, Lyon. jannik.laval@univ-lyon2.fr
}

\begin{abstract}
Human-centered project-based teaching methods have proved their efficiency and popularity in the last decade. Such practice emphasizes the existence of interdisciplinary skills that students manipulate and incrementally learn to master throughout their higher education curriculum. This paper addresses some questions around the integration and evaluation of interdisciplinary skills. The first question focuses on the establishment of a skill-based approach to keep track of the students' competencies over human-centered computing skills all along their curriculum. To this end, we discuss the advantages and disadvantages of existing approaches in the context of agile practices and interdisciplinary skills in human-centered project-based teaching methods. The second question deals with the tools that can accompany such approach and how they can affect the teaching courses, the university instructors' habits and the motivation of the students. A semi-structured interviews were conducted with five instructors regarding these two questions. One main conclusion is the need to keep track of the students progress during the courses to help an efficient follow up. For this end, we propose to co-design a framework named APACHES.
\end{abstract}

Keywords: Human Centered Computer Sciences · Agile Project · Traceability · Skill Based Approach · Learning Analytic.

\section{Context}

Today, we notice a lack of awareness regarding human-centered project-based teaching methods in higher education, partly caused by the deficiency in existing tools to help university instructors integrate such approaches to their courses. Consequently, students lack knowledge of such methods and skills such as agile project management skills in concrete contexts. Furthermore, when used, the focus in project-based teaching approaches tends to be from a project management point of view and rarely on the Human and Social Sciences aspects. 
An existing agile project based method is formalized by ALPES (agile based learning in higher education) [5]. The objective is to give to the students the concepts of project management using agile approaches. These are integrated in various disciplinary courses all along the curriculum. ALPES is inspired from social constructivism, promoting the co-construction of knowledge and skills rather than the transmission of knowledge. Thus, it insists on the human interactions.

Another existing approach, THEDRE [3] (Traceable Human Experiment Design) provides a method for conducting Research in Human-Centered Computer Sciences (RHCCS). The purpose of RHCCS is the construction and evaluation of instruments by and for humans. Such research requires an experimental approach to produce and analyze field data by integrating the human in both design and evaluation. To be complete, this experimental approach must also take into account the context in which humans evolve. RHCCS requires proceeding in successive steps to build and evaluate instruments. The objective of THEDRE is to propose the RHCCS process that accompanies the researcher and the conceptual and technical tools to ensure the traceability of such process.

In this paper, we present the motivation behind the APACHES ${ }^{6}$ project, which goal is to provide both a theoretical framework and tools to train undergraduate, graduate, $\mathrm{PhD}$ students, university instructors and supervisors on human-centered project management and human-centered research methods. The project is part of an ambitious skill-based approach throughout the higher education curriculum. APACHES will rely on the two aforementioned methods (ALPES and THEDRE), not to replace the human in project-based courses, but to support the different actors in the education process. APACHES is therefore concerned by the mastery of the method in order to reuse it in other contexts.

\section{WAAT: Web Application for APACHES Tools}

To define the different features to integrate into the APACHES framework, we have chosen to apply a participatory design approach [4] by identifying the practices and needs of university instructors. We interviewed five of them who apply, in a way or another, principles of the ALPES method during their courses. The interviews were based on qualitative questions to evaluate the current state of use of the human-centered project-based approaches in undergraduate courses and to identify how to improve and reinforce such practices (this collect was recommended by tools offered by THEDRE). First, university instructors shared with us a number of ALPES method concepts and tools that they use in their courses. The most commonly used one (used by all the interviewees) is the decomposition of the project into a number of independent user stories. Each user story is divided into tasks. A user story should answer to a need or intention from the user point of view and an education objective from a pedagogical point of view. Other commonly used tools are the planning board and task board 1 and the tweetback board (a tool for the students to give feedback). These boards allow to visualize the overall project organization and furthermore permit to trace

\footnotetext{
${ }^{6}$ Funded by the I-Site ULNE (University of Lille, North Europe) foundation.
} 

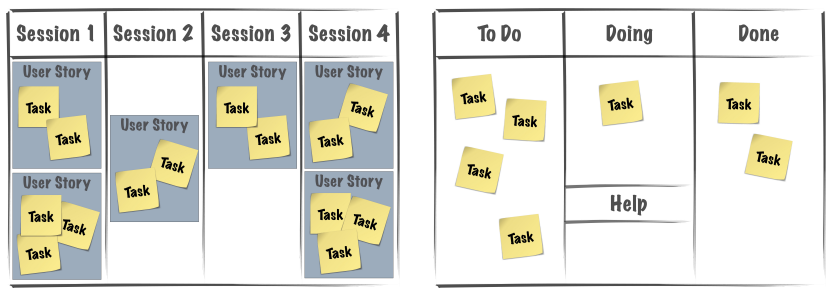

Fig. 1. Planning Board (left) and Task Board (right)

the student progress in the project and courses. These boards are materialized by papers and post-it notes (representing user stories or tasks). According to 3 "The boards are efficient for the visibility over what we should expect from the course and what we are heading for. This is reassuring for the students and therefore for their university instructor".

According to the interviews, the APACHES tool should allow to (1) dematerialize the boards in order to collect the students' traces to understand and optimize the learning and the environments in which it occurs [1]); (2) design a learning dashboard that helps the university instructor to have a global vision of progress of all the students in the class [6].

Some instructors are particularly interested by the idea of possible assistance issued from trace-based analysis. Through progress estimation from trace analysis, WAAT will be able to provide skill based personalized assistance [2] to them and their students. However, others are more reluctant to that idea, and were concerned that such a feature would tend to make instructors too dependent on the tools; number 5 said "It should be an aid tool to trace their work and detect indicators. It should not stop or replace the communication with the students".

\section{Summary}

The project will implement human-centered, iterative, incremental and adaptive methodology, thus respecting the concepts that we wish to transmit and recommend [3]. The designed approach, tools and concepts will be based on and inspired from ALPES, THEDRE methods, agile approaches and research methods for human-centered computer sciences (Fig.2). It will be integrated into undergraduate courses or addressed in dedicated courses on agile approaches in graduate level courses in engineer schools and university. Based on a model domain and the participatory design involving instructors, the APACHES method allows to design and develop WAAT, a tool that will include an instructor dashboard and allow to keep track of students' progresses during courses.

This will be evaluated throughout its starting in September 2019. A first iteration of experiments on the first version of WAAT tool will be done by volunteer university instructors. In addition to this group, we will select a panel of representative students to identify their needs and propositions to refine the tools and the method. The second iteration will concern the modalities of transmitting the 


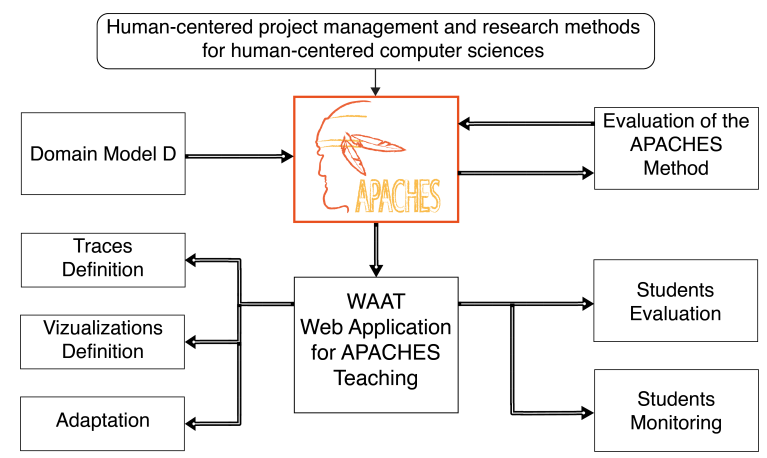

Fig. 2. The APACHES project

method to other instructors and how the tool can accompany them in transforming their courses. During the training, we will do regular interviews with them to understand their appropriation and the diffusion of the method.WAAT will allow to collect student activity traces, allowing an a posteriori analysis. In the long term, such data can help in developing student monitoring indicators. To build and evaluate the different indicators, we will use a user-centered approach as prescribed by THEDRE. Thus, we will involve the instructors in the three steps of this process: exploring their needs, co-constructing the indicators and evaluating them. To ensure the follow-up of this work, we will use confirmed protocols $^{7}$ for each step. APACHES involves more than 2000 students in three french institutions, more than $15 \mathrm{PhD}$ students and 13 instructors in order to transform the teaching of human-centered computer sciences.

\section{References}

1. Ferguson, R.: Learning analytics: drivers, developments and challenges. International Journal of Technology Enhanced Learning 4(5-6), 304-317 (Jan 2012)

2. Heller, J., Steiner, C., Hockemeyer, C., Albert, D.: Competence-based knowledge structures for personalised learning. Int. J. on E-learning 5(1), 75-88 (2006)

3. Mandran, N., Dupuy-Chessa, S.: THEDRE: A Traceable Process for High Quality in Human Centred Computer Science Research. In: Information Systems Development: Advances in Methods, Tools and Management (ISD2017 Proceedings). Paspallis, N. et al. (Eds.), Lanarca, Cyprus (2017)

4. Muller, M.J., Kuhn, S.: Participatory Design. Commun. ACM 36(6), 24-28 (Jun 1993)

5. Vermeulen, M., Fleury, A., Fronton, K., Laval, J.: Les alpes: Approches agiles pour l'enseignement supérieur. In: QPES 2015 conference (2015)

6. Xhakaj, F., Aleven, V., McLaren, B.M.: Effects of a teacher dashboard for an intelligent tutoring system on teacher knowledge, lesson planning, lessons and student learning. In: European Conference on Technology Enhanced Learning. pp. 315-329. Springer (2017)

\footnotetext{
7 The digital notebook for collabor-active learning https://labnbook.fr/
} 